\title{
At first sight: how do restrained eaters evaluate high- fat palatable foods?
}

Citation for published version (APA):

Roefs, A. J., Herman, C., Macleod, C., Smulders, F. T. Y., \& Jansen, A. T. M. (2005). At first sight: how do restrained eaters evaluate high-fat palatable foods? Appetite, 44, 103-114.

https://doi.org/10.1016/j.appet.2004.08.001

Document status and date:

Published: 01/01/2005

DOI:

10.1016/j.appet.2004.08.001

Document Version:

Publisher's PDF, also known as Version of record

\section{Document license:}

Taverne

\section{Please check the document version of this publication:}

- A submitted manuscript is the version of the article upon submission and before peer-review. There can be important differences between the submitted version and the official published version of record.

People interested in the research are advised to contact the author for the final version of the publication, or visit the DOI to the publisher's website.

- The final author version and the galley proof are versions of the publication after peer review.

- The final published version features the final layout of the paper including the volume, issue and page numbers.

Link to publication

\footnotetext{
General rights Owners
rights.

- You may freely distribute the URL identifying the publication in the public portal. please follow below link for the End User Agreement:

www.umlib.nl/taverne-license

Take down policy

If you believe that this document breaches copyright please contact us at:

repository@maastrichtuniversity.nl

providing details and we will investigate your claim.
}

Copyright and moral rights for the publications made accessible in the public portal are retained by the authors and/or other copyright owners and it is a condition of accessing publications that users recognise and abide by the legal requirements associated with these

- Users may download and print one copy of any publication from the public portal for the purpose of private study or research.

- You may not further distribute the material or use it for any profit-making activity or commercial gain

If the publication is distributed under the terms of Article $25 \mathrm{fa}$ of the Dutch Copyright Act, indicated by the "Taverne" license above, 


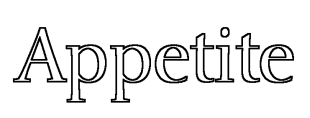

Appetite 44 (2005) 103-114

www.elsevier.com/locate/appet

\title{
Research Report
}

\section{At first sight: how do restrained eaters evaluate high-fat palatable foods?}

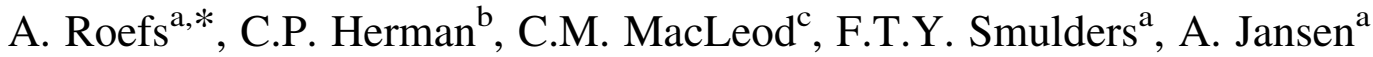 \\ ${ }^{a}$ Department of Experimental Psychology, Faculty of Psychology (UNS 40), Maastricht University, \\ P.O. Box 616, 6200 MD Maastricht, The Netherlands \\ ${ }^{\mathrm{b}}$ Department of Psychology, University of Toronto, 100 St. George Street, Toronto, Ontario, Canada M5S $3 G 3$ \\ ${ }^{\mathrm{c}}$ Department of Psychology, University of Waterloo, 200 University Avenue West, Waterloo, Ontario, Canada N2L 3G1
}

Received 24 May 2004; revised 6 July 2004; accepted 2 August 2004

\begin{abstract}
Two experiments tested the hypothesis that restrained eaters display a greater liking for high-fat palatable foods, than do unrestrained eaters. This hypothesis was tested in the affective priming paradigm [Fazio, R. H., Sanbonmatsu, D. M., Powell, M. C., \& Kardes, F. R. (1986). On the automatic activation of attitudes. Journal of Personality and Social Psychology, 50, 229-238] and in the extrinsic affective Simon task [De Houwer, J. (2003a). The extrinsic affective Simon task. Experimental Psychology, 50, 77-85]. Both paradigms were successful in uncovering food likes and dislikes, and both showed that participants were able to evaluate the palatability of foods relatively automatically. However, contrary to the hypothesis, food likes were not substantially affected by fat content, nor were they affected by restraint-status. Restrained and unrestrained eaters may like high-fat palatable foods to the same extent, but may differ in their craving for these foods.
\end{abstract}

(C) 2004 Elsevier Ltd. All rights reserved.

Keywords: Restrained eaters; Food likes; Indirect measures; Affective priming paradigm; Extrinsic affective Simon task

\section{Introduction}

What determines which foods people choose to consume? This question is difficult to answer given the many factors that could influence food choice (Mela, 1999, 2001), factors such as palatability, health concerns, and availability. One of the most important of these factors seems to be the palatability (liking) of the food (Eertmans, Baeyens, \& Van den Bergh, 2001), a factor that affects almost everyone. Moreover, there may also exist individual differences in the liking of foods, governed by such characteristics as one's body weight and the extent to which one desires to control that weight. In the current research, we are interested in

\footnotetext{
* Corresponding author.

E-mail address: a.roefs@psychology.unimaas.nl (A. Roefs).
}

precisely those individual differences in food liking. The first question that arises is how these differences can best be measured.

Some studies (Gerding \& Weinstein, 1992) have been conducted in which participants were simply asked to report what kinds of food they like. An obvious disadvantage of this kind of measure is that socially desirable answering tendencies can be fairly strong. It might not be easy to admit a liking for high-fat foods in a society in which being slim is considered very important, and in which obesity is stigmatized (Puhl \& Brownell, 2003; Teachman \& Brownell, 2001). To try to overcome the disadvantages of questionnaires, Lamote, Hermans, Baeyens, and Eelen (2004) used an indirect measure to assess food likes and dislikes. More specifically, they used the affective priming paradigm (Fazio, Sanbonmatsu, Powell, \& Kardes, 1986) to study food likes and dislikes in a healthy population. 
The results of their study suggest that the affective priming paradigm is a suitable measure to uncover people's food likes and dislikes.

The affective priming paradigm is one of the indirect measures that have recently become very popular in clinical psychology (Palfai \& Ostafin, 2003; Sherman, Rose, Koch, Presoon, \& Chassin, 2003) and social psychology (Dovidio, Kawakami, \& Gaertner, 2002; Fazio, Jackson, Dunton, \& Williams, 1995). In this paradigm (Fazio et al., 1986; Klauer $\&$ Musch, 2003) two stimuli are presented in quick succession, a prime followed by a target. No response is required to the prime, which is simply displayed and replaced by the target. Participants have to respond to the target by evaluating it in terms of it is associated with positive versus negative affect. The dependent variable is the positive/negative key-press latency in response to the target.

The focus of the priming paradigm is on the extent to which the presentation of the prime influences the response to the target. Typically (Bargh, Chaiken, Govender, \& Pratto, 1992; Fazio et al., 1986; Hermans, De Houwer, \& Eelen, 1994, 2001), affectively congruent prime-target pairs (e.g. 'love'- 'happy') lead to shorter response latencies to the target word than do affectively incongruent prime-target pairs (e.g. love-'awful'). This in itself is not surprising, and is consistent with semantic priming effects more generally (see Neely, 1991). The critical idea is that the pattern of response latencies as a function of affect match between prime and target indicates how people evaluate the prime on a fairly automatic level. Applied to the palatability of food, if people respond faster on congruent trials ('palatable-positive' and 'unpalatablenegative') than on incongruent trials ('palatable-negative' and 'unpalatable-positive'), it can be inferred that they like palatable foods more than unpalatable foods. The main advantage of employing such indirect measures is that they can estimate people's evaluations of various stimuli without directly asking (Fazio \& Olson, 2003), thereby possibly reducing the risk of socially desirable answering tendencies. Responses are assumed to be relatively automatic in this kind of task, because stimuli are presented in quick succession and participants are urged to respond as quickly as possible, leaving insufficient time for controlled processing ${ }^{1}$ (Hermans, De Houwer et al., 2001).

\footnotetext{
${ }^{1}$ Using an indirect measure is not necessarily equivalent to the measurement of an unconscious construct. Participants may be unaware what the task assesses, but that does not necessarily mean that they are unaware of their attitudes or evaluations (Fazio \& Olson, 2003). Thus, the term automatic is not equivalent to the term unconscious, but rather means that the employed indirect measures leave insufficient time for participants to strategically control their response. To avoid confusing terminology, we follow Fazio and Olson (2003) (see e.g. MacLeo, 1989) in using the term indirect measure instead of implicit measure, and the term direct measure instead of explicit measure, because 'implicit' seems to carry the notion of 'unconscious', while 'explicit' seems to carry the notion of 'conscious'.
}

Whereas Lamote et al. (2004) showed that the affective priming paradigm is useful for assessing food likes and dislikes in general, the major aim of the current experiments is to study whether this paradigm and a related indirect measure are sensitive to individual differences between restrained and unrestrained eaters in food likes and dislikes. Heatherton, Herman, Polivy, King, and McGree (1988, p. 19) define restrained eaters, as selected by the Restraint Scale (Herman \& Polivy, 1980), as dieters who 'exhibit periods of restraint punctuated by episodes of disinhibited overeating'. Thus, restrained eaters have the intention of controlling their weight, but often fail and indulge in high-fat palatable foods that they normally do not allow themselves to eat (Herman \& Polivy, 1980, 2004). As Gendall and Joyce (2001) suggest, the eating behavior of restrained eaters might enhance the attractiveness of these normally forbidden foods, because of psychological frustration and temporary deprivation. Although evidence is not unequivocal, several self-report studies (Gendall, Joyce, Sullivan, \& Bulik, 1998; Pelchat, 1997) found more craving in restrained as compared to unrestrained eaters. Moreover, some studies (Herman, Polivy, Klajner, \& Esses, 1981; Klajner, Herman, Polivy, \& Chhabra, 1981; LeGoff \& Spigelman, 1987) found evidence for stronger physiological reactivity toward food cues in restrained than unrestrained eaters, though again evidence is not unequivocal (Nederkoorn \& Jansen, 2002). The current studies will investigate whether this possibly greater craving and physiological reactivity in restrained eaters is accompanied by a greater liking of these foods on a relatively automatic level.

Prior research in our laboratory also focused on individual differences in food likings, but used another indirect measure (Roefs \& Jansen, 2002), the Implicit Association Test (IAT; Greenwald, McGhee, \& Schwartz, 1998). Contrary to the hypothesis that an obese group would have a stronger liking of high-fat foods than of low-fat foods than a lean control group (see e.g. Drewnowski, Brunzell, Sande, Iverius, \& Greenwood, 1985; Rissanen et al., 2002), both groups showed more negative associations with high-fat foods than with lowfat foods, with this effect being more pronounced for the obese group. The unexpected results of Roefs and Jansen (2002) can probably most easily be explained by the specific characteristics of the IAT, in that the fat content of the food is very salient for participants in this task. The results of De Houwer's studies (2001, 2003b) suggest that IAT effects are strongly influenced by the basis of categorization (in our case fat content: high-fat vs. low-fat). It is perhaps unsurprising that people do not like the fact that their favorite food is high-fat, though they obviously like the taste of it.

The advantage of both the priming task (Fazio et al., 1986) and another, recently developed indirect measure, the extrinsic affective Simon task (EAST; De Houwer, 
2003a), is that these tasks do not demand that the food be categorized in terms of fat content, thereby avoiding a specific focus on the fat content (cf. IAT). Thus, indirect measures may not all assess the same underlying construct (Bosson, Swann, \& Pennebaker, 2000; Fazio \& Olson, 2003; Olson \& Fazio, 2003; but see Cunningham, Preacher, \& Banaji, 2001). Because of these and other disadvantages of the IAT (De Houwer, 2002) we chose to continue our research on individual differences in food likings using other indirect measures. In Experiment 1, the affective priming paradigm will be employed (Fazio et al., 1986), following the lead of Lamote et al. (2004). In Experiment 2, a recently developed paradigm, the EAST (De Houwer, 2003a), will be employed, to seek convergence and generalization in a different paradigm. Similar to the affective priming paradigm, participants are not required to categorize the foods into pre-defined categories. Both experiments investigate whether restrained eaters display a stronger liking of palatable foods over unpalatable foods than unrestrained eaters, and whether this is specific for highfat palatable foods, the foods that restrained eaters normally do not allow themselves to eat.

\section{Experiment 1}

\section{Method}

\section{Participants}

The participants were female introductory psychology students at the University of Toronto. They were selected on the basis of their score on the Restraint Scale (Herman \& Polivy, 1980) from a large group of students who had indicated that they would like to participate in research, and they took part either for bonus credit in a course or for $\$ 10$. Thirty-two participants were classified as restrained eaters, indicated by a score of 15 or higher on the Restraint Scale (age: $M=19.5, \mathrm{SD}=2.0$; selfreported weight $(\mathrm{kg}): M=63.0, \mathrm{SD}=10.2 ; \mathrm{BMI}: M=$ 22.9, $\mathrm{SD}=3.3$, Range $=17.1-30.8$; total score Restraint Scale: $M=20.0, \mathrm{SD}=3.6)$. Thirty-seven participants were classified as unrestrained eaters, indicated by a score of 14 or lower on the Restraint Scale (age: $M=19.5, \mathrm{SD}=$ 1.8; self-reported weight $(\mathrm{kg}): M=55.7, \mathrm{SD}=7.7$; $\mathrm{BMI}$ : $M=20.6, \quad \mathrm{SD}=2.6, \quad$ Range $=16.5-28.2 ;$ total score Restraint Scale: $M=8.1, \mathrm{SD}=3.3$ ). BMI refers to body mass index, which is simply the ratio of weight to squared height $\left(\mathrm{kg} / \mathrm{m}^{2}\right)$. The two groups did not differ significantly in age, $t(67)<1$. However, they did differ in BMI, $t(67)=3.24, p<0.01$. The data of one additional participant (restrained eater) were deleted from all analyses because of a high percentage $(>M+3 \mathrm{SD})$ of trials with errors or responses that were either too slow $(>2000 \mathrm{~ms})$ or too fast $(<200 \mathrm{~ms})$.
Stimulus selection and timing of trials in the priming task

Stimuli. Sixteen high-fat food words (e.g. 'chocolate') and 16 low-fat food words (e.g. 'melon') served as primes (see Appendix A). The two groups of stimuli did not differ significantly in word length (number of letters: high-fat: $M=6.3, \mathrm{SD}=1.4$ vs. low-fat: $M=6.1, \mathrm{SD}=$ $1.5), t(30)<1$. These foods were selected on the basis of both a food table (Nevo Tabel, 1993) and prior research related to food and restraint (McCabe, 1999).

Thirty-two general positive (e.g. 'love') and 32 general negative (e.g. 'dreadful') words served as targets (see Appendix A), and were selected according to norms by Bellezza, Greenwald, and Banaji (1986), who had participants rate a large number of words on 5-point scales for pleasantness (very unpleasant-very pleasant), visual imagery (no image at all-very clear and vivid visual image), and familiarity (encounter very infrequently-encounter very frequently). The two groups of stimuli differed significantly in pleasantness (negative: $M=1.4, \mathrm{SD}=0.1$ vs. positive: $M=4.6, \mathrm{SD}=0.1, t(62)=$ $118.29, p<0.001$. There were no significant differences between the two groups of stimuli in visual imagery (negative: $M=3.6, \mathrm{SD}=0.5$ vs. positive: $M=3.7, \mathrm{SD}=$ $0.5), t(62)<1$, affective extremity (negative: $M=1.6$, $\mathrm{SD}=0.1$ vs. positive: $M=1.6, \mathrm{SD}=0.1), t(62)=1.39$, $p=0.17$, or word length (negative: $M=6.4, \mathrm{SD}=1.2 \mathrm{vs}$. positive: $M=6.1, \mathrm{SD}=1.7), t(62)<1$. However, there was a significant difference in familiarity ratings (negative: $M=2.8, \mathrm{SD}=0.6$ vs. positive: $M=3.5, \mathrm{SD}=$ $0.6), t(62)=4.73, p<0.001$. Primes and targets were presented in black lower-case letters $(6 \mathrm{~mm}$ high) against a light background on a computer monitor.

Randomization of stimuli. Each of the 3 blocks consisted of 64 trials, resulting in a total of 192 trials. Each food-stimulus (prime) was paired once with a positive and once with a negative target in each block. All primes had been presented once (with either a positive or a negative target) before any prime was presented for the second time in each block. For each set of two participants (one restrained and one unrestrained eater), and for each of the three blocks, it was determined randomly which half of the high-fat foods and which half of the low-fat foods would be paired first with a positive/negative target. Primes and targets were both randomly selected (uniquely for each participant) from their respective sets without replacement.

Trial timing. The timing of trials was modeled after the procedure of Hermans, De Houwer, et al. (2001). Each trial started with a warning tone $(200 \mathrm{~ms})$, followed by a fixation cross $(500 \mathrm{~ms})$. Then, the prime was presented for $200 \mathrm{~ms}$. After a $150 \mathrm{~ms}$ stimulus onset asynchrony (SOA) - the time that elapses between the onset of the prime and the onset of the target-the target was presented on the monitor. Thus, prime and target cooccurred for $50 \mathrm{~ms}$. An SOA of $150 \mathrm{~ms}$ was chosen because Hermans, De Houwer et al. (2001) showed that 
this SOA was optimal for the expression of affective priming effects. Because of the $50 \mathrm{~ms}$ simultaneous presentation, the prime was presented $4.5 \mathrm{~mm}$ above the center of the monitor, and the target $4.5 \mathrm{~mm}$ below the center of the monitor (as measured to the center-line of the characters). ${ }^{2}$ The target remained on the monitor until a response was given or for $2500 \mathrm{~ms}$ if no response was given. If an error was made or a response was either too slow or too fast, or if no response at all was given, a warning appeared on the screen for $300 \mathrm{~ms}$. The intertrial interval was $2500 \mathrm{~ms}$.

\section{Direct measures}

Direct rating task of foods. The 32 foods that were used as primes were presented in random order (identical for all participants) on a paper-and-pencil rating task. Participants were asked to rate the foods on taste (5-point scale: 1 : dislike a lot - 5: like a lot).

Direct rank order task. Participants were given two separate lists, one with the high-fat foods (16) and one with the low-fat foods (16), presented in the same random order for all participants. They were asked to rank each list of foods in order of how much they liked the taste, from the most tasty item to the least tasty item. The high-fat and lowfat foods were presented on separate lists to minimize influences of socially desirable answering tendencies. If these two types of food had been presented mixed in one list, participants might have been 'tempted' to give the low-fat foods a better rank, even though they were instructed to pay attention only to the taste of the foods.

This direct ranking task was included specifically for the purpose of stimulus selection for the priming task. Because the palatability of foods likely varies widely among participants (Frank \& van der Klaauw, 1994), we decided to determine prime palatability uniquely for each participant. On the basis of the direct rank order task, we selected the 5 most liked items, and the 5 least liked items for each type of food (high-fat and low-fat) for each participant. To prevent the direct ranking task from interfering with the priming task, all primes (32) were initially included in the priming task. In the analyses, we used only those trials on which one of the idiosyncratically selected 20 primes appeared (40 trials per block). Selecting primes in this way provided us with 5 high-fat palatable foods, 5 low-fat palatable foods, 5 high-fat unpalatable foods, and 5 low-fat unpalatable foods per participant.

Restraint Scale. The Restraint Scale measures 'the extent to which participants showed evidence of dieting and concern about their weight' (Herman \& Polivy, 1980,

\footnotetext{
${ }^{2}$ Note however that the uncentered presentation mode might have underestimated a possible priming effect involving fat content (Hermans, De Houwer, et al., 2001). This way of presenting stimuli was chosen, because originally this experiment included a second part in which the SOA was varied, but in which the prime presentation was to be held constant at $200 \mathrm{~ms}$.
}

p. 212). The maximum score on this scale is 35 , whereas the minimum score is 0 .

\section{Procedure}

Participants were tested individually in a quiet research room. For the affective priming task, they were instructed to read the first word silently, and then to decide whether the second word was positive or negative, pressing the corresponding key on the key box (key assignment was counterbalanced across participants). They were told to respond as quickly as possible but to avoid making too many mistakes. They were then presented with 16 practice trials using stimulus materials different from those on the experimental trials. Similarly to Zack, Toneatto, and MacLeod (1999), they were given a free recall test for the primes immediately after the practice trials, writing down as many words as they could remember that appeared as a first word (prime) on the computer task that they had just performed. This task was included to ensure that participants paid attention to both primes and targets by raising the possibility that participants might be asked to perform such a free recall task later in the procedure. After this memory test, a brief reminder appeared on the monitor concerning how to perform the priming task. Participants were now ready to begin the actual priming task, which was made up of three blocks with a short break after each block.

After the priming task, the participants were again given a free recall test for the primes. Subsequently, a manipulation check was performed, to check whether participants realized what the computer task assessed. Next, participants were asked to perform the rating and rank-ordering of the foods as described in Section 2.1.3. Their final task was to complete the Restraint Scale.

\section{Apparatus}

The experiment was carried out on a Dell Inspiron 5000e notebook computer with a Pentium III processor, connected to a Samsung SyncMaster 750S monitor. Key responses were registered by an external response device with better than $1 \mathrm{~ms}$ accuracy. The software controlling the experiment was programmed in ERTS (Experimental Run Time System, Beringer, 1996).

\section{Design and analysis}

Data were analyzed using a 2(target affect: positive vs. negative $) \times 2$ (fat content prime: high-fat vs. low-fat $) \times$ 2(palatability of prime: palatable vs. unpalatable) $\times$ 2(group: restrained vs. unrestrained) analysis of variance (ANOVA), with repeated measures on the first three factors. An interaction between prime and target indicates that there is a priming effect (i.e. that the presentation of the prime influenced the speed and accuracy of responding to the target). Before analyzing the data, we discarded responses that were either too fast $(<200 \mathrm{~ms})$ or too slow $(>2000 \mathrm{~ms}$ ), a total of only $0.19 \%$ of all trials. 
Response latencies associated with error responses (4.5\%) were also discarded. All reported analyses are for response latencies as the dependent variable. Analyses on error percentages will not be reported because they did not produce relevant significant results.

\section{Results}

\section{Affective priming task ${ }^{3}$}

The speed of the response to the target was influenced by the palatability of the prime in the expected direction: participants were on average faster on congruent (palatable-positive/unpalatable-negative) than on incongruent (palatable-negative/unpalatable-positive) trials. This prime palatability $\times$ target affect interaction was significant, $F(1,67)=5.87, p<0.05$, and qualified main effects of both target affect, $F(1,67)=9.48, p<0.01$, and prime palatability, $F(1,67)=5.11, p<0.05$ (see Fig. 1). This interaction effect (i.e. priming effect) means that participants displayed a liking of palatable foods over unpalatable foods on a relatively automatic level. However, this effect did not seem to be different for the restrained and unrestrained groups, as indicated by the non-significant target affect $\times$ prime palatability $\times$ group interaction, $F(1,67)<1$. Moreover, the fat content did not seem to influence the results. None of the relevant interactions - target affect $X$ prime fat content $(X$ group) and target affect $\times$ prime fat content $\times$ prime palatability ( $\times$ group) —was significant, all $F \mathrm{~s}(1,67)<1.39$. Nor were the main effects of prime fat content, $F(1,67)<1$, or group $F(1,67)=1.88, \mathrm{p}=0.18$, significant.

\section{Direct rating task palatability}

Data for ratings of all 32 foods were analyzed. In a 2 (fat content: high-fat vs. low-fat) $\times 2$ (group: restrained vs. unrestrained) ANOVA. On the direct task, participants in general indicated that they preferred the tastes of low-fat foods to those of high-fat foods, $F(1,67)=11.46, p<0.01$, a finding which may partly reflect disapproval of high-fat foods, rather than genuine dislike. Neither the main effect of group, nor the fat content $\times$ group interaction was significant, both $F \mathrm{~s}(1,67)<1$ (Table 1$)$.

An analysis was also performed on just the five most palatable high-fat and low-fat items and the five most unpalatable high-fat and low-fat items, to examine whether

\footnotetext{
${ }^{3}$ In the reported analyses, one participant was excluded because of a high percentage $(>M+3 \mathrm{SD})$ of trials with errors or responses that were either too slow $(>2000 \mathrm{~ms})$ or too fast $(<200 \mathrm{~ms})$. Analyses including this participant did not affect the latency results. In the error analyses, however, the target affect $\times$ prime palatability $\times$ group interaction was marginally significant $(p=0.07)$. In separate analyses for the two groups, the target affect $\times$ prime palatability interaction was not significant for the restrained eaters $(F<1)$, but was marginally significant for the unrestrained eaters $(p=0.07)$. Unrestrained participants made fewer errors on incongruent trials (palatable prime — negative target/unpalatable prime-positive target) than on congruent trials (palatable prime-positive target/unpalatable prime-negative target).
}

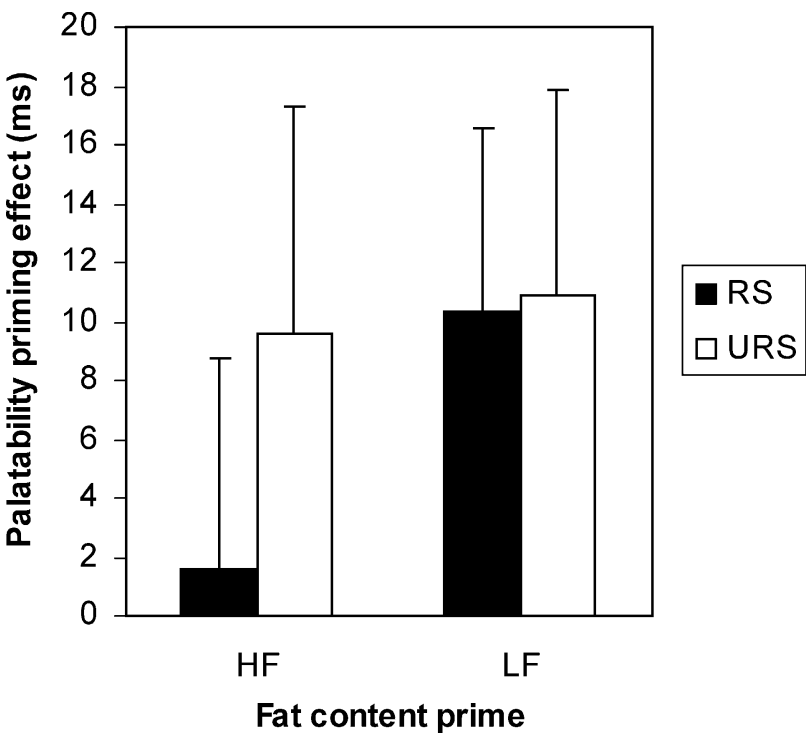

Fig. 1. Experiment 1: The palatability priming effect as a function of participant group (restrained vs. unrestrained eaters) and fat content of the prime. The palatability priming effects for each participant and separately for high-fat and low-fat foods are computed as: ((mean (palatable -$)+$ mean $($ unpalatable +$)) / 2)-(($ mean $($ palatable +$)+$ mean $($ unpalatable ))/2). In this formula, 'palatable' or 'unpalatable' indicate the palatability of the prime, whereas the plus or minus sign right behind it, indicate whether the target was positive or negative. A positive score indicates a liking of palatable foods over unpalatable foods, and a negative score indicates a liking of unpalatable foods over palatable foods. Error bars represent one standard error. Note: RS = restrained eaters; URS = unrestrained eaters; $\mathrm{HF}=$ high-fat food; $\mathrm{LF}=$ low-fat food.

the high-fat and low-fat foods differed in palatability rating within these extreme fives, in a 2(palatability: top five palatable vs. top five unpalatable) $\times 2$ (fat content: high-fat vs. low-fat) $\times 2$ (group) ANOVA. The palatability factor was based on the responses on the rank order task. Participants strongly preferred the palatable items over the unpalatable items, $F(1,67)=767.33, p<0.001$, which is in accordance with the findings on the affective priming task. Participants again also preferred the low-fat foods over the high-fat

Table 1

Experiment 1: Mean palatability ratings (1: very unpalatable - 5: very palatable) of the direct rating task

\begin{tabular}{|c|c|c|c|c|}
\hline \multirow[t]{2}{*}{ Food } & \multicolumn{2}{|c|}{ Mean } & \multicolumn{2}{|l|}{ SD } \\
\hline & $\mathrm{RS}$ & URS & $\mathrm{RS}$ & URS \\
\hline $\mathrm{HF}$ & 3.8 & 3.8 & 0.6 & 0.5 \\
\hline LF & 4.1 & 4.0 & 0.4 & 0.5 \\
\hline $\mathrm{HF}+$ & 4.7 & 4.7 & 0.4 & 0.3 \\
\hline $\mathrm{HF}-$ & 2.6 & 2.6 & 0.9 & 0.8 \\
\hline $\mathrm{LF}+$ & 4.8 & 4.8 & 0.2 & 0.3 \\
\hline $\mathrm{LF}-$ & 3.0 & 3.0 & 0.7 & 0.9 \\
\hline
\end{tabular}

Standard deviations (SD) are reported in a separate column. The high-fat and low-fat foods are grouped into palatable and unpalatable foods based on the direct rank order task. Note: $\mathrm{HF}=$ all $\mathrm{HF}$ foods; $\mathrm{LF}=$ all low-fat foods; $\mathrm{HF}+=$ high-fat palatable foods; $\mathrm{HF}-=$ high-fat unpalatable foods; $\mathrm{LF}+=$ low-fat palatable foods $\mathrm{LF}-=$ low-fat unpalatable foods; $\mathrm{RS}=$ restrained eaters, URS $=$ unrestrained eaters. 
foods, $F(1,67)=14.18, p<0.001$. Moreover, the palatability $\times$ fat content interaction was significant, $F(1,67)=$ $7.92, p<0.01$. Further analyses indicate that the effect of fat content was larger for unpalatable items, $F(1,67)=13.47$, $p<0.001$, than for palatable items, $F(1,67)=4.41, p<0.05$ (see Table 1).

\section{Experiment 2}

We sought to corroborate the findings of Experiment 1 in a second experiment, which tested the same hypothesis in a different, converging way. Experiment 2 differed in three important ways from Experiment 1. First, to study whether the findings of Experiment 1 might have been method specific, a different indirect measure, the EAST (De Houwer, 2003a), was used in Experiment 2. Comparable to the affective priming paradigm, this paradigm also does not demand that the food stimuli be categorized in predefined categories (high-fat vs. low-fat). Second, in Experiment 2, the palatability factor was determined not only on an individual basis, as in Experiment 1, but also on the basis of a separate pilot study, conducted with a different group of participants. So, using the pilot data, the four groups of stimuli were determined on an a priori basis. This manipulation permits comparison of these two methods of stimulus selection. The advantage of an idiosyncratic measure of palatability for stimulus selection is that this procedure guarantees that the selected stimuli fit with the participant. The advantage of stimulus selection based on a pilot study is that the stimuli that are used in the analyses are the same for all participants. Finally, a third modification involved how the positive and negative stimuli (in this experiment the white words) were selected. In Experiment 1 , the target words were simply general positive and negative words. These sets of stimuli were chosen to avoid biasing the participants, and thus their responses to the primes (foods). In Experiment 2, synonyms of the concepts 'palatable' and 'unpalatable' were used as the white stimuli, in an attempt to make the (un)palatability a salient feature.

\section{Method}

\section{Pilot study palatability}

The goal of this pilot study was to determine which foods are generally liked and disliked by female university students $(n=64)$. Participants were given a list of 28 highfat foods and a list of 33 low-fat foods, and were asked to consider each list separately. If high-fat and low-fat foods had been mixed, participants might have been tempted to select mainly low-fat foods, because a liking for low-fat foods may be seen as socially desirable. They were asked to choose from each list the eight foods that they liked most and the eight foods that they disliked most. Then, they were asked to rank the eight foods they (dis)liked most from 1 ((dis)like the most) to 8 ((dis)like the least).
Stimulus selection was based on the mean ranking of a food, weighted by the number of participants who put that food in their selection of (dis)liked foods. In this way, we selected 5 high-fat liked, 5 high-fat disliked, 5 low-fat liked, and 5 low-fat disliked foods (see Appendix A).

\section{Participants}

The participants were female students at Maastricht University in the Netherlands. Participants were selected in the same way as in Experiment 1. All participants were paid $€ 7.50$. Twenty-six participants, scoring 15 or higher on the Restraint Scale, were classified as restrained eaters (age: $M=19.6, \mathrm{SD}=2.2$; weight $(\mathrm{kg}): M=69.0, \mathrm{SD}=13.2$; $\mathrm{BMI}$ : $M=24.6, \quad \mathrm{SD}=4.16, \quad$ Range $=19.8-34.4 ;$ total score Restraint Scale: $M=20.3, \mathrm{SD}=4.0$ ). Thirty participants, scoring 14 or lower on the Restraint Scale, were classified as unrestrained eaters (age: $M=19.3, \mathrm{SD}=1.1$; weight $(\mathrm{kg})$ : $M=63.6, \mathrm{SD}=7.8 ; \mathrm{BMI}: M=22.3, \mathrm{SD}=2.4$, Range $=$ 18.6-27.1; total score Restraint Scale: $M=10.1, \mathrm{SD}=2.9$ ). The experimenter measured body weight and height at the end of the experiment. Two restrained eaters did not want to be weighed, and did not want to report their weight either. The two groups did not differ significantly in age, $t(54)<1$. They did differ significantly in BMI, $t(34.95)=2.43$, $p<0.05$.

\section{Overview extrinsic affective Simon task (EAST)}

In the critical blocks of the EAST (De Houwer, 2003a), white and colored (blue vs. green) stimuli were presented intermixed. Participants had to categorize the white words based on the meaning of these words, and the colored words based on their color. The white stimuli were synonyms of the concept palatable or the concept unpalatable. By assigning one type of white stimuli (e.g. synonyms of palatable) to the left response key, and the other type of white stimuli (e.g. synonyms of unpalatable) to the right response key, participants extrinsically associated each key with a specific type of stimuli. Key-assignment was counterbalanced over participants.

The colored stimuli were the concepts of interest, and consisted of the same four types of food as in Experiment 1. Each food stimulus was presented once in blue and once in green in each experimental block. The participant was instructed to respond to one color (e.g. blue) with the left response key, and to respond to the other color (e.g. green) with the right response key. Again, key assignment was counterbalanced over participants. In this example, it should be easier for a participant to categorize the color of a palatable food when it is presented in blue rather than green, because both blue food words and white synonyms of the concept palatable map onto the same response key (left). Correspondingly, it should be easier for a participant to categorize the color of an unpalatable food when it is presented in green rather than blue, because both green food words and white synonyms of the concept unpalatable map onto the same response key (right). The dependent variables 
in this task were the response latency and the percentage of errors. The EAST effect is defined as the difference in response latency and/or error percentages when responding with the extrinsically incongruent key versus the extrinsically congruent key.

\section{Stimulus selection and timing of the trials in the EAST}

Stimuli. Five high-fat palatable $(\mathrm{HF}+)$, five high-fat unpalatable $(\mathrm{HF}-)$, five low-fat palatable $(\mathrm{LF}+)$, and five low-fat unpalatable $(\mathrm{LF}-$ ) foods were selected as colored stimuli, on the basis of the pilot task (see Appendix A). These four groups of stimuli did not differ significantly in word length (number of letters: $\mathrm{HF}+: M=6.2, \mathrm{SD}=1.8$; $\mathrm{HF}-: M=6.2, \mathrm{SD}=1.9 ; \mathrm{LF}+: M=6.4, \mathrm{SD}=2.2 ; \mathrm{LF}-$ : $M=7.2, \mathrm{SD}=1.1), F(3,16)<1$.

The white stimuli were 5 synonyms for the concept palatable and 5 synonyms for the concept unpalatable (see Appendix A). These stimuli were selected using the online version of the Van Dale Dictionary for the Dutch language. The two groups of stimuli did not differ significantly in word length (number of letters: synonyms palatable: $M=8.0$, $\mathrm{SD}=2.7$; synonyms unpalatable: $M=8.4, \mathrm{SD}=3.4), t(8)<$ 1. Stimuli were presented against a black background. Following De Houwer (2003a), using the RGB color system, the blue color was defined as $0 \%$ red, $38 \%$ green, and $46 \%$ blue, whereas the green color was defined as $0 \%$ red, $46 \%$ green, and $38 \%$ blue. The resulting blue and green colors were distinguishable but rather similar, as was intended.

Randomization of stimuli. In the first block, the 10 white words were presented twice in a random order unique for each participant. Stimuli were drawn without replacement, and the set was initialized when it was empty. In the second block, each food word was presented once in a random order unique for each participant. Half of the foods were presented in green, the other half in blue. The color (blue or green) of the presented stimulus was also determined randomly and was unique for each participant.

The four experimental blocks followed, in each of which there were 20 white trials and 40 colored trials. The colored trials were the crucial trials, and all food words were presented once in each color, in each block. All words were presented once in either green or blue before any words were presented for the second time in the other color. For each pair of two participants (one restrained and one unrestrained eater), and for each of four experimental blocks, it was determined randomly which half of the stimuli would be presented first in green, and which half would be presented first in blue. Again, all stimuli were drawn randomly from their respective sets without replacement, unique for each participant and each block. Sets were initialized when they were empty. Following De Houwer (2003a), each test block started with a few warm-up trials (four in the first test block, two in the other three test blocks). Each of the 10 white words appeared on one of these warm-up trials. The selection of the white words for the warm-up trials was random (unique for each participant). In each block, half of the warm-up trials were positive and the other half were negative.

Trial timing. The timing of the trials was modeled after that of De Houwer (2003a). Each trial started with a white fixation cross in the middle of the monitor $(500 \mathrm{~ms})$. Then, the stimulus was presented in the color appropriate for that trial (white, green, or blue), also in the middle of the monitor. The stimulus remained on the monitor until the participant responded, or until $10 \mathrm{~s}$ had elapsed. The intertrial interval was $1500 \mathrm{~ms}$. If an error was made, or a response was either too slow $(>3000 \mathrm{~ms})$ or too fast $(<$ $300 \mathrm{~ms}$ ), or if no response at all was given, a warning appeared on the monitor for $300 \mathrm{~ms}$. We changed the cutoffs in this experiment relative to Experiment 1, to closely follow De Houwer's (2003a) procedure, thereby also generalizing presentation parameters.

\section{Direct measures}

The same kind of direct measures were used as in Experiment 1 . Of course, this time, only the 20 foods that appeared in the EAST were presented on these direct measures. In the paper-and-pencil rating task, participants were asked to rate the foods on taste (7-point scale: dislike a lot-like a lot).

The ranking task was the same as in Experiment 1 and was used as an idiosyncratic measure of palatability. EAST data were then analyzed in two ways: with a palatability factor based on the pilot study (all 5 stimuli for each of 4 food types), and with a palatability factor based on this idiosyncratic measure. For the idiosyncratic measure of palatability, the three most palatable and the three most unpalatable high-fat and low-fat foods were selected for each participant and used in the analyses. A final direct measure was the Restraint Scale (Herman \& Polivy, 1980).

\section{Procedure}

Participants were tested individually in a quiet, dimly lit research room. First, general instructions were given about which key to press to what kind of stimulus in the EAST. Responses had to be given as quickly as possible, avoiding too many mistakes. Before each block, the relevant instructions were repeated on the monitor. After each block, participants could take a quick break. To control for time of day effects (e.g. time elapsed since lunch or breakfast), average start time of the test session did not differ significantly between the two groups, $t(54)<1$. After the EAST, participants were asked to perform the rating and rank order task on the foods. Then, they were asked to fill out the Restraint Scale. Afterward, participants were briefly asked about their dieting history, eating habits, and medical condition. Finally, the experimenter measured the participant's height and weight. 


\section{Apparatus}

The experiment was carried out on a Dell Optiplex GX 110 computer with a Pentium III processor, connected to a Dell monitor. The same external response device and the same software package as in Experiment 1 were used.

\section{Design and analysis}

EAST results were analyzed in 2(fat content food words: high-fat vs. low-fat) $\times 2$ (palatability food words: palatable vs. unpalatable $) \times 2$ (extrinsic response: synonym palatable vs. synonym unpalatable) $\times 2$ (group: restrained vs. unrestrained eaters) ANOVAs, with repeated measures on the first three factors. An interaction between a food factor and the extrinsic response indicates a significant EAST effect. All analyses were performed on the colored trials only, the trials on which food words were presented. Using the same cut-off values as De Houwer (2003a) did for his EAST studies, responses that were either too fast $(<300 \mathrm{~ms})$ or too slow ( $>3000 \mathrm{~ms}$ ) were discarded, a total of only $0.28 \%$ of all trials in the analysis with the pilot based palatability factor, and $0.17 \%$ of all trials for the analysis with the idiosyncratic palatability factor. Response latencies associated with error responses (pilot-based: $4.7 \%$; idiosyncratic measure: $4.3 \%$ ) were also discarded.
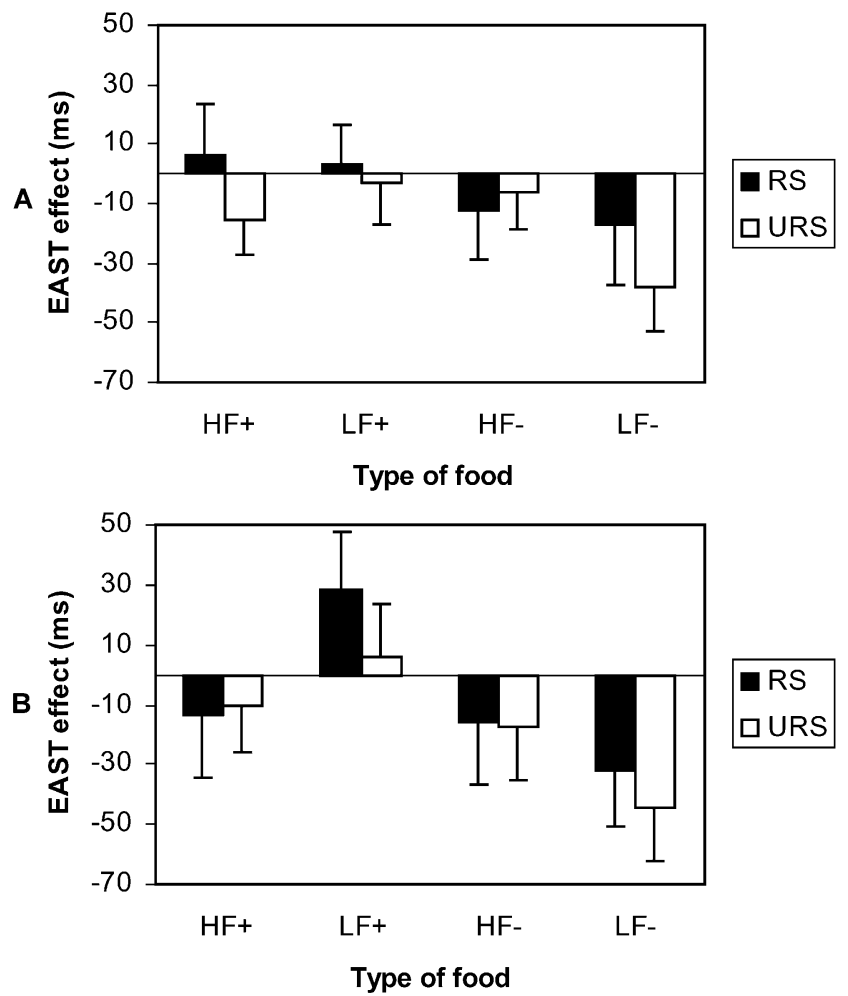

\section{Results and discussion}

\section{Palatability based on pilot study}

Response latencies. No significant effects emerged from this analysis. The EAST effect, palatability $\times$ extrinsic response, $F(1,54)=2.40, p=0.13$, was not significant (see Fig. 2A).

Percentage errors. Unrestrained eaters made fewer errors as compared to restrained eaters, $F(1,54)=4.38$, $p<0.05$. Moreover, the EAST effect, palatability $\times$ extrinsic response was significant and in the expected direction, $F(1$, $54)=8.81, p<0.01$. On colored trials with palatable items, participants made fewer errors when responding with the extrinsic palatable response than when responding with the extrinsic unpalatable response, $F(1,54)=4.92, p<0.05$, whereas the opposite was true for colored trials with unpalatable items. Participants then made fewer errors when responding with the extrinsic unpalatable response, $F(1$, $54)=5.54, p<0.05$. However, the EAST effect (palatability $\times$ extrinsic response) was not modified by the fat content of the foods, $F(1,54)<1$, the restraint-status of the participant, $F(1,54)<1$, or an interaction between restraint-status and fat content, $F(1,54)<1$ (see Fig. 2A).
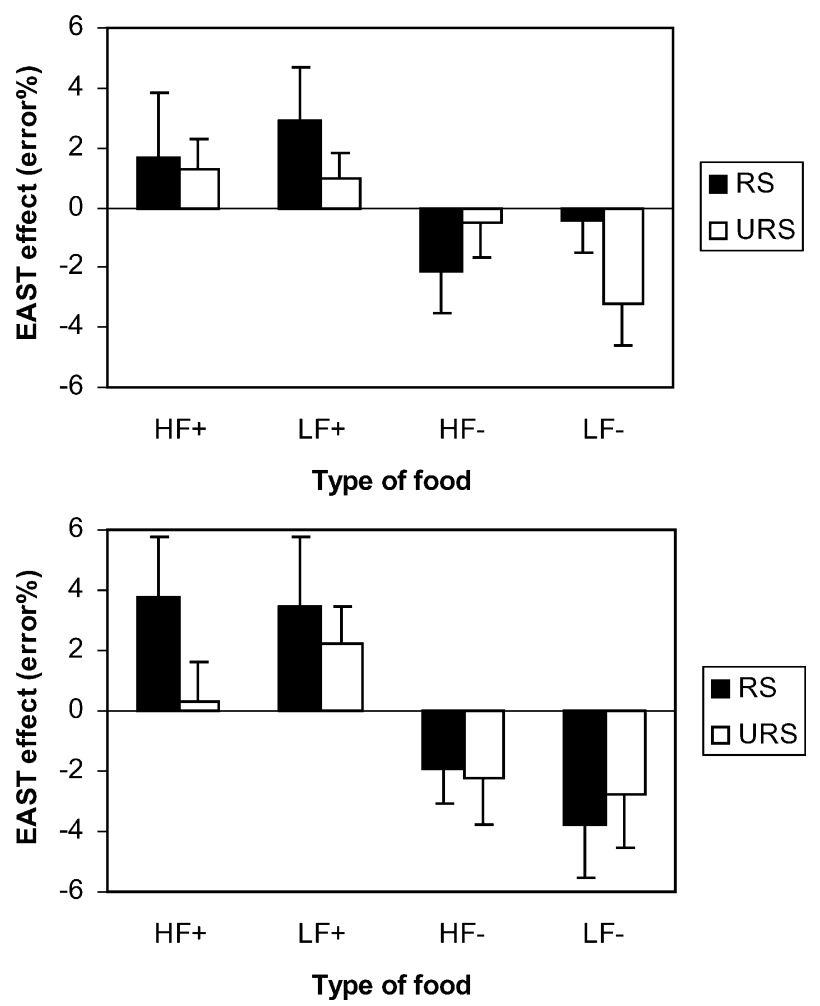

Fig. 2. Experiment 2: The EAST effect as a function of participant group (restrained vs. unrestrained eaters), palatability of the food, and fat content of the food. The EAST effect (RT and percentage of errors) for each participant and separately for each type of food is computed as: (extrinsic unpalatable responseextrinsic palatable response). A positive score indicates a relative liking of the type of food, whereas a negative score indicates a relative disliking of the type of food. Error bars represent one standard error. Panel A represents the results for the analyses with the palatability factor based on the pilot study. Panel B represents the results for the analyses with the palatability factor based on the idiosyncratic rankings. The left panels represent the results for the response latencies, whereas the right panels represent the results for the error percentages. Note: $\mathrm{RS}=$ restrained eaters; URS $=$ unrestrained eaters; HF $+=$ high-fat palatable food; $\mathrm{LF}+=$ low-fat palatable food; $\mathrm{HF}-=$ high-fat unpalatable food; $\mathrm{LF}-=$ low-fat unpalatable food. 
Idiosyncratic measure of palatability

Response latencies. A fat content $\times$ palatability $\times$ extrinsic response interaction, $F(1,54)=6.06, p<0.05$, qualified a palatability $\times$ extrinsic response interaction, $F(1,54)=$ $7.77, p<0.01$. For high-fat foods, the palatability $\times$ extrinsic response interaction was not significant, $F(1,54)<1$. For low-fat foods, the palatability $\times$ extrinsic response interaction was significant, $F(1,54)=11.78, p<0.01$. On colored trials with unpalatable items, participants were faster when responding with the extrinsic unpalatable response than when responding with the extrinsic palatable response, $F(1,54)=8.57, p<0.01$. For palatable items, this main effect of extrinsic response was not significant, $F(1$, $54)=1.63, p=0.21$ (see Fig. 2B). This three-way interaction was not modified by restraint-status, $F(1,54)<1$.

Percentage errors. The EAST effect, palatability $\times$ extrinsic response, was significant, $F(1,54)=12.71, p<$ 0.01 . On colored trials with palatable items, participants made fewer errors when responding with the extrinsic palatable response than when responding with the extrinsic unpalatable response, $F(1,54)=5.97, p<0.05$, whereas the opposite was true for colored trials with unpalatable items. Participants then made fewer errors when responding with the extrinsic unpalatable response, $F(1,54)=9.61, p<0.01$. However, the EAST effect (palatability $\times$ extrinsic response) was not modified by the fat content of the foods, $F(1,54)<1.14$, the restraint-status, $F(1,54)<1$ or an interaction between fat content and restraint-status, $F(1$, 54) $<1$ (see Fig. 2B).

\section{Direct rating task palatability}

Data were analyzed in a 2(fat content: high-fat vs. lowfat) $\times 2$ (palatability: palatable vs. unpalatable) $\times 2$ (group: restrained vs. unrestrained eaters) ANOVA. The palatability factor was based on the pilot study. Unsurprisingly, the palatable items were judged to be more palatable than the unpalatable items, $F(1,54)=318.10, p<0.001$, which is in accordance with the findings on the EAST. A fat content $X$ palatability interaction, $F(1,54)=9.53, p<0.01$, qualifying the main effect of palatability, suggests that the difference between palatable and unpalatable items was larger for the high-fat foods than for the low-fat foods (see Table 2).

Table 2

Experiment 2: Mean palatability ratings (1: very unpalatable - 7: very palatable) of the direct rating task

\begin{tabular}{llllll}
\hline Food & Mean & & & \multicolumn{2}{l}{ SD } \\
\cline { 2 - 3 } \cline { 5 - 6 } \cline { 5 - 6 } & RS & URS & & RS & URS \\
\hline HF+ & 6.0 & 6.1 & 0.8 & 0.6 \\
HF- & 3.6 & 3.9 & & 1.0 & 1.0 \\
LF+ & 5.9 & 5.9 & & 0.5 & 0.6 \\
LF- & 4.2 & 4.1 & & 1.0 & 1.0 \\
\hline
\end{tabular}

Standard deviations (SD) are reported in a separate column. Note: $\mathrm{HF}+=$ high-fat palatable foods; $\mathrm{HF}-=$ high-fat unpalatable foods; $\mathrm{LF}+=$ lowfat palatable foods; $\mathrm{LF}-=$ low-fat unpalatable foods; $\mathrm{RS}=$ restrained eaters, $\mathrm{URS}=$ unrestrained eaters.
Again, results were not influenced by the restraint-status of the participants, $F \mathrm{~s}(1,54)<1.40$.

\section{General discussion}

The goal of the current experiments was to test the hypothesis that restrained eaters would be characterized by a stronger liking of (high-fat) palatable foods. To do so, we employed two indirect measures: the affective priming paradigm (Fazio et al., 1986) and the EAST (De Houwer, 2003a), seeking to provide convergence and generalization. In Experiment 1, the affective priming task, participants were faster on congruent (palatable-positive/unpalatable-negative) trials than on incongruent (palatablenegative/unpalatable-positive) trials. In Experiment 2 (EAST), participants responded more accurately to palatable food words when these food words-which had to be categorized based on their color (green vs. blue)-were mapped onto the same response key as synonyms of the concept palatable. Similarly, participants responded more accurately to unpalatable food words when these food words - which had to be categorized based on their colorwere mapped onto the same response key as synonyms of the concept unpalatable. Moreover, in Experiment 2, results were not substantially affected by the way that the palatable and unpalatable stimuli had been selected (idiosyncratically vs. pilot study). EAST effects were a little more consistent for the low-fat foods, in that in the $R T$ analyses (idiosyncratic measure of palatability) an EAST effect was only observed for the low-fat foods. In the analyses on error percentages, EAST effects were not influenced by the fat content of the foods.

The results of both experiments suggest that people in general can and do evaluate the palatability of foods quite automatically. The evaluation of the palatability of the food is automatic in the sense that the two paradigms did not allow much time for controlled processing because of the relatively short presentation durations and quick responding. The hypothesis that restrained eaters would show a stronger liking for (high-fat) palatable foods was not supported in either experiment. Note, however, that the conclusion of no differences between restrained and unrestrained eaters hinges on a null-finding, so power may have been a problem. But it is worth noting that the finding that people make this early response toward food based on its taste is consistent with prior research. Hermans, Baeyens, and Lamote (2001) and Lamote et al. (2004) found an affective priming effect for foods based on general liking for these foods.

Why did we not find evidence for the principal hypothesis that restrained eaters would show a stronger liking for (high-fat) palatable foods? If it is assumed that greater craving necessarily is accompanied by greater liking (for a discussion of this assumption, see Berridge, 1996), then the results of the current experiments could be taken as evidence that restrained eaters are not characterized by 
differential craving responses toward high-fat palatable foods. It could also be that the stimuli-names of foodsthat were used in the current studies were not strong enough cues to elicit more craving in restrained eaters as compared to unrestrained eaters, and thus did not lead to differential liking responses.

An alternative explanation can be found in Berridge's (1996) theory of food reward. Though it is often assumed that a craving for a food reflects liking the food, he convincingly argues that this in fact might not always be the case, and that there is no independent evidence for it. $\mathrm{He}$ distinguishes between appetite and palatability, a distinction between 'the disposition to eat and the sensory pleasure of actually eating' (p. 4). Berridge prefers to use the common word 'wanting' for the motivational effects of appetite and the word 'liking' for the palatability effects. In Berridge's (1996) analysis, people can experience an increase in wanting (craving), without experiencing an increase in liking (increased palatability). Thus, our results could mean that a possibly increased craving response toward high-fat palatable foods in restrained eaters simply does not go together with a stronger liking for the food, even if this liking is assessed by an indirect measure. These indirect measures may thus tap the palatability or liking of the food independent of craving for that food.

Consequently, it might thus be the case that all people, independent of restraint-status, like certain foods to the same extent, but that restrained eaters have a stronger wanting for those foods. An indication that restrained eaters have a stronger wanting of certain foods is that-apart from the studies cited in Section 1 suggesting that restrained eaters have more cravings and stronger physiological reactivity to food cues - they often do have a higher weight and a higher energy intake (French et al., 1994; Jansen, 1996; Stice, 2002). Moreover, as Nederkoorn, van Eijs, and Jansen (2004) recently showed, restrained eaters are more impulsive than unrestrained eaters on a computer task that is unrelated to eating behavior, the stop-signal task (Logan, 1994). As Nederkoorn et al. (2004) suggest, this impulsivity might very well underlie their dysfunctional eating behavior. In other words, restrained eaters might be less able to resist the temptation of palatable food.

Wiers, van Woerden, Smulders, and de Jong (2002) draw similar conclusions from their findings, based on the incentive-sensitization theory (Robinson \& Berridge, 2001). This theory resembles Berridge's (1996) theory of food reward. According to Robinson and Berridge (2001), an addiction is driven by a stronger wanting (sensitized arousal) of the drug or alcohol, and not by a greater liking of it. Wiers et al. (2002) used an IAT (Greenwald et al., 1998), and found that heavy drinkers associated alcohol more strongly with arousal than did light drinkers. Heavy and light drinkers did not differ in their valence associations: they invariably associated alcohol with negative affect. 'These arousal associations could reflect an appetitive response directed toward the drug' (alcohol) (Wiers et al., 2002, p. 656).

Notably, in the current experiments, we found evidence for positive associations with palatable foods. This was not specific for restrained eaters or for high-fat foods, but-in contrast to Wiers et al. (2002) study in which negative alcohol associations were found-we found liking of palatable foods over unpalatable foods. Importantly, Wiers et al. (2002) used a different indirect measure, the IAT (Greenwald et al., 1998). As explained in Section 1, these indirect measures often do not correlate strongly (Bosson et al., 2000; Fazio \& Olson, 2003; Olson \& Fazio, 2003), which might suggest that these paradigms measure different underlying constructs, although reliability and validity are also concerns (Buchner \& Wippich, 2000). Thus, the difference in paradigms (IAT vs. affective priming and EAST) might explain why Wiers et al. (2002)—like Roefs and Jansen (2002) - found negative associations with the supposedly craved substance, whereas the current experiments found positive associations.

In sum, palatability, not fat content, determined responding for all individuals, regardless of their restraint-status. No evidence was found for the hypothesis that restrained eaters would show a greater liking of (high-fat) palatable foods. If it is assumed that liking a food and craving for a food are necessarily related, these findings could be taken as evidence that restrained eaters are not characterized by stronger craving responses specifically toward high-fat palatable foods, as compared to unrestrained eaters. However, that assumption appears doubtful. The wantin$\mathrm{g} /$ liking distinction of Berridge (1996) was suggested as a relevant dimension that might help to explain the behavior observed here, in that this theory states that craving and liking might be independent processes. It thus may be that restrained and unrestrained eaters do differ in craving responses toward high-fat palatable foods, despite liking these foods to the same extent. The employed indirect measures might only be sensitive to liking responses (palatability) and not to potential differences in craving. At any rate, the factors involved in food likes and cravings, and how they interact with the characteristics of the individual eater, clearly represent a complex structure.

\section{Acknowledgements}

This study was financed by the Netherlands Research Organization (NWO) Grant 425-20-801, awarded to Anita Jansen. The authors would like to thank Reinout Wiers, Jorg Huijding, Peter de Jong, and Martin Zack for advice on the design of the current studies, Gerard van Breukelen for his advice on the statistical analyses, Beatrijs Hauer for testing the participants of Experiment 2, and Marieke Werrij and Pascal van Gerven for their comments on an earlier draft of this article. Correspondence concerning this article should 
be addressed to Anne Roefs: a.roefs@psychology.unimaas.nl [A. Roefs].

\section{Experiment 1}

Positive targets: love, romantic, paradise, pleasure, joy, laughter, cheer, humor, passion, terrific, enjoyment, happy, caress, cuddle, honest, life, freedom, hug, peace, liberty, treasure, triumph, loyal, sweetheart, truth, warmth, cozy, glory, reward, flower, talent, honor.

Negative targets: killer, torture, devil, rape, brutal, funeral, murderer, bastard, morgue, poison, burial, dreadful, suicide, agony, failure, hatred, poverty, terrible, abuse, unhappy, accident, hostage, despise, disaster, bankrupt, jail, filth, slime, violent, grief, waste, tragedy.

High-fat foods: bacon, cake, cheese, chips, chocolate, coconut, cookie, donut, fries, fudge, hamburger, herring, nachos, pancake, peanuts, walnuts.

Low-fat foods: apple, banana, bread, broccoli, cabbage, fruit, juice, melon, radish, popcorn, rice, spinach, strawberry, tomato, turkey, yogurt.

\section{Experiment 2}

Synonyms palatable: smakelijk (palatable), heerlijk (delicious), lekker (tasty), verrukkelijk (delectable), zalig (yummy).

Synonyms unpalatable: vies (vile), smerig (nasty), afschuwelijk (horrible), walgelijk (disgusting), onsmakelijk (unpalatable).

High-fat palatable foods: chocola (chocolate), chips (chips), friet (fries), croissant (croissant), pizza (pizza).

High-fat unpalatable foods: haring (herring), speklap (slice of bacon), pate (pate), boter (butter), pindakaas (peanutbutter).

Low-fat palatable foods: aardbeien (strawberries), druiven (grapes), meloen (melon), kip (chicken), popcorn (popcorn).

Low-fat unpalatable foods: spruiten (Brussels sprouts), witlof (chicory), zuurkool (sauerkraut), andijvie (endive), radijs (radish).

\section{References}

Bargh, J. A., Chaiken, S., Govender, R., \& Pratto, F. (1992). The generality of the automatic attitude activation effect. Journal of Personality and Social Psychology, 62, 893-912.

Bellezza, F. S., Greenwald, A. G., \& Banaji, M. R. (1986). Words high and low in pleasantness as rated by male and female college students. Behavior Research Methods, Instruments, and Computers, 18, 299303.

Beringer, J. (1996). Experimental run time system (ERTS). [Computer software]. Frankfurt, Germany: Berisoft.

Berridge, K. C. (1996). Food reward: Brain substrates of wanting and liking. Neuroscience and Biobehavioral Reviews, 20, 1-25.
Bosson, J. K., Swann, W. B., Jr.., \& Pennebaker, J. W. (2000). Stalking the perfect measure of implicit self-esteem: The blind men and the elephant revisited? Journal of Personality and Social Psychology, 79, 631-643.

Buchner, A., \& Wippich, W. (2000). On the reliability of implicit and explicit memory measures. Cognitive Psychology, 40, 227-259.

Cunningham, W. A., Preacher, K. J., \& Banaji, M. B. (2001). Implicit attitude measures: Consistency, stability, and convergent validity. Psychological Science, 12, 163-170.

De Houwer, J. (2001). A structural and process analysis of the Implicit Association Test. Journal of Experimental Social Psychology, 37, 443451

De Houwer, J. (2002). The Implicit Association Test as a tool for studying dysfunctional associations in psychopathology: Strengths and limitations. Journal of Behavior Therapy and Experimental Psychiatry, 33, 115-133.

De Houwer, J. (2003a). The extrinsic affective Simon task. Experimental Psychology, 50, 77-85.

De Houwer, J. (2003b). A structural analysis of indirect measures of attitudes. In J. Musch, \& K. C. Klauer (Eds.), The psychology of evaluation: Affective processes in cognition and emotion (pp. 219-244). Mahwah, NJ: Erlbaum.

Dovidio, J. F., Kawakami, K., \& Gaertner, S. L. (2002). Implicit and explicit prejudice and interracial interaction. Journal of Personality and Social Psychology, 82, 62-68.

Drewnowski, A., Brunzell, J. D., Sande, K., Iverius, P. H., \& Greenwood, M. R. C. (1985). Sweet tooth reconsidered: Taste responsiveness in human obesity. Physiology and Behavior, 35, 617-622.

Eertmans, A., Baeyens, F., \& Van den Bergh, O. (2001). Food likes and their relative importance in human eating behavior: Review and preliminary suggestions for health promotion. Health Education Research, 16, 443-456.

Fazio, R. H., Jackson, J. R., Dunton, B. C., \& Williams, C. J. (1995). Variability in automatic activation as an unobtrusive measure of racial attitudes: A bona fide pipeline? Journal of Personality and Social Psychology, 69, 1013-1027.

Fazio, R. H., \& Olson, M. A. (2003). Implicit measures in social cognition research: Their meaning and use. Annual Review of Psychology, 54, 297-327

Fazio, R. H., Sanbonmatsu, D. M., Powell, M. C., \& Kardes, F. R. (1986). On the automatic activation of attitudes. Journal of Personality and Social Psychology, 50, 229-238.

Frank, R. A., \& van der Klaauw, N. J. (1994). The contribution of chemosensory factors to individual differences in reported food preferences. Appetite, 22, 101-123.

French, S. A., Jeffery, R. W., Forster, J. L., McGovern, P. G., Kelder, S. H., \& Baxter, J. E. (1994). Predictors of weight change over two years among a population of working adults: The healthy worker project. International Journal of Obesity, 18, 145-154.

Gendall, K. A., \& Joyce, P. R. (2001). Characteristics of food cravers who binge eat. In M. M. Hetherington (Ed.), Food cravings and addiction (pp. 567-583). London: Leatherhead Publishing.

Gendall, K. A., Joyce, P. R., Sullivan, P. F., \& Bulik, C. M. (1998). Food cravers: Characteristics of those who binge. International Journal of Eating Disorders, 23, 353-360.

Gerding, A. L., \& Weinstein, L. (1992). Taste ratings of obese people, and taste preferences based on geographical location. Bulletin of the Psychonomic Society, 30, 509-510.

Greenwald, A. G., McGhee, D. E., \& Schwartz, J. L. K. (1998). Measuring individual differences in implicit cognition: The Implicit Association Test. Journal of Personality and Social Psychology, 74, 115-139.

Heatherton, T. F., Herman, C. P., Polivy, J., King, G. A., \& McGree, S. T (1988). The (mis)measurement of restraint: An analysis of conceptual and psychometric issues. Journal of Abnormal Psychology, 97, 19-28.

Herman, C. P., \& Polivy, J. (1980). Restrained eating. In A. J. Stunkard (Ed.), Obesity (pp. 208-225). Philadelphia, PA: Saunders. 
Herman, C. P., \& Polivy, J. (2004). The self-regulation of eating: Theoretical and practical problems. In R. F. Baumeister, \& K. D. Vohs (Eds.), Handbook of self-regulation research (pp. 492-508). New York: Guilford Press.

Herman, C. P., Polivy, J., Klajner, F., \& Esses, V. M. (1981). Salivation in dieters and non-dieters. Appetite, 2, 356-361.

Hermans, D., Baeyens, F., \& Lamote, S. (2001). Affective priming as an implicit and unobtrusive measure of attitudes towards food items. Unpublished research report, University of Leuven, Belgium.

Hermans, D., De Houwer, J., \& Eelen, P. (1994). The affective priming effect: Automatic evaluative information in memory. Cognition and Emotion, 8, 515-533.

Hermans, D., De Houwer, J., \& Eelen, P. (2001). A time course analysis of the affective priming effect. Cognition and Emotion, 15, 143-165.

Jansen, A. (1996). How restrained eaters perceive the amount they eat. British Journal of Clinical Psychology, 35, 381-392.

Klajner, F., Herman, C. P., Polivy, J., \& Chhabra, R. (1981). Human obesity, dieting, and anticipatory salivation to food. Physiology and Behavior, 27, 195-198.

Klauer, K. C., \& Musch, J. (2003). Affective priming: Findings and theories. In J. Musch, \& K. C. Klauer (Eds.), The psychology of evaluation: Affective processes in cognition and emotion (pp. 7-49). Mahwah, NJ: Erlbaum.

Lamote, S., Hermans, D., Baeyens, F., \& Eelen, P. (2004). An exploration of affective priming as an indirect measure of food attitudes. Appetite, 42, 279-286.

LeGoff, D. B., \& Spigelman, M. N. (1987). Salivary responses to olfactory food stimuli as a function of dietary restraint and body weight. Appetite, 8, 29-35.

Logan, G. D. (1994). On the ability to inhibit thought and action: A users' guide to the stop signal paradigm. In D. Dagenbach, \& T. H. Carr (Eds.), Inhibitory processes in attention, memory, and language (pp. 189-239). San Diego: Academic Press.

MacLeod, C. M. (1989). Directed forgetting affects both direct and indirect tests of memory. Journal of Experimental Psychology: Learning, Memory, and Cognition, 15, 13-21.

McCabe, R. E. (1999). Cognitive aspects of restraint: Situational and task influences on memory for body shape-related information in dieters and non-dieters. Unpublished doctoral dissertation, University of Toronto.

Mela, D. J. (1999). Symposium on 'Functionality of nutrients and behaviour'. Food choice and intake: The human factor. Proceedings of the Nutrition Society, 58, 513-522.

Mela, D. J. (2001). Determinants offood choice: Relationships with obesity and weight control. Paper presented at Food patterns in weight management and health, Dallas, TX

Nederkoorn, C., \& Jansen, A. (2002). Cue reactivity and regulation of food intake. Eating Behaviors, 3, 61-72.
Nederkoorn, C., Van Eijs, Y., \& Jansen, A. (2004). Restrained eaters act on impulse. Personality and Individual Differences doi:10.1016/j.paid.2004.02.020.

Neely, J. H. (1991). Semantic priming effects in visual word recognition: A selective review of current findings and theories. In D. Besner, \& G. W. Humphreys (Eds.), Basic processes in reading: Visual word recognition (pp. 264-337). Hillsdale, NJ: Erlbaum.

Nevo Tabel, Nederlands voedingsstoffenbestand (1993). Den Haag, The Netherlands [Dutch Food Composition Table].

Olson, M. A., \& Fazio, R. H. (2003). Relations between implicit measures of prejudice: What are we measuring? Psychological Science, 14, 636-639.

Palfai, T. P., \& Ostafin, B. D. (2003). The influence of alcohol on the activation of outcome expectancies: The role of evaluative expectancy activation in drinking behavior. Journal of Studies on Alcohol, 64, 111-119.

Pelchat, M. L. (1997). Food cravings in young and elderly adults. Appetite, 28, 103-113.

Puhl, R., \& Brownell, K. D. (2003). Ways of coping with obesity stigma: Review and conceptual analysis. Eating Behaviors, 4, 53-78.

Rissanen, A., Hakala, P., Lissner, L., Mattlar, C. E., Koskenvuo, M., \& Rönnemaa, T. (2002). Acquired preference especially for dietary fat and obesity: A study of weight-discordant monozygotic twin pairs. International Journal of Obesity, 26, 973-977.

Robinson, T. E., \& Berridge, K. C. (2001). Mechanisms of action of addictive stimuli: Incentive-sensitization and addiction. Addiction, 96, $103-114$.

Roefs, A., \& Jansen, A. (2002). Implicit and explicit attitudes toward highfat foods in obesity. Journal of Abnormal Psychology, 111, 517-521.

Sherman, S. J., Rose, J. S., Koch, K., Presson, C. C., \& Chassin, L. (2003). Implicit and explicit attitudes toward cigarette smoking: The effects of context and motivation. Journal of Social and Clinical Psychology, 22, 13-39.

Stice, E. (2002). Risk and maintenance factors for eating pathology: A meta-analytic review. Psychological Bulletin, 128, 825-848.

Teachman, B. A., \& Brownell, K. D. (2001). Implicit anti-fat bias among health professionals: Is anyone immune? International Journal of Obesity, 25, 1525-1531.

Wiers, R. W., van Woerden, N., Smulders, F. T. Y., \& de Jong, P. J. (2002). Implicit and explicit alcohol-related cognitions in heavy and light drinkers. Journal of Abnormal Psychology, 111, 648-658.

Zack, M., Toneatto, T., \& MacLeod, C. M. (1999). Implicit activation of alcohol concepts by negative affective cues distinguishes between problem drinkers with high and low psychiatric distress. Journal of Abnormal Psychology, 108, 518-531. 